\title{
Spinal cord compression in Paget's disease
}

\author{
NiALL E. F. CARTLIDGE, JOHN P. K. MCCOLLUM, \\ AND RAM D. A. AYYAR \\ From the Department of Neurology, Royal Victoria Infirmary, \\ Queen Victoria Road, Newcastle upon Tyne
}

SUMMARY Three cases of spinal cord compression secondary to Paget's disease of the spine are reported. In two of the cases a relatively short history with pain as a prominent feature suggested initially a diagnosis of extradural malignancy. The usual clinical features of this rare disorder are discussed and the characteristic radiological findings are emphasized.

The importance of the early recognition of spinal cord compression due to benign lesions needs no emphasis. Among such lesions, Paget's disease of bone is well recognized and, although rare, it has several characteristic features (Wyllie, 1923; Hartman and Dohn, 1966; Miller, 1967; Siegelman, Levine, and Walpin, 1968; Feldman and Seaman, 1969; Direkze and Milnes, 1970). Furthermore, as results of decompression may be very good (Latimer, Webster, and Gurdjian, 1953), its diagnosis is vital (Siegelman et al., 1968).

Characteristically, spinal cord compression due to Paget's disease occurs in middle-aged males and usually in the thoracic region. In most recorded cases the history of paraparesis has been of about one year's duration (Aldren Turner, 1940; Latimer et al., 1953) and approximately $50 \%$ of cases have had local and girdle pain over a similar period. The radiological appearance of the vertebral bodies may not always be diagnostic but when a partly calcified paravertebral mass is demonstrated, or when there is involvement of the neural arch, the nature of the lesion is in little doubt (Latimer et al., 1953; Direkze and Milnes, 1970).

We report here three cases seen in neurological practice in this city in the course of a year, all with unusual features.

\section{CASE 1}

A 50 year old male was admitted to hospital in March 1969. Over the preceding four months he had suffered from increasing mid-dorsal back pain with radiation in girdle distribution aggravated by coughing. During the latter two months he developed progressive numbness, stiffness, and weakness in both legs. There was no sphincter disturbance and general health was otherwise good. On examination there was tenderness over the eighth thoracic vertebra and the left tibia was bowed and thickened. He had a moderate spastic paraparesis with impaired joint position and vibration sense in both legs. There was impairment of pain and temperature sensation to the level of the eighth thoracic dermatome.

Laboratory findings were: haemoglobin $17.8 \mathrm{~g} /$ $100 \mathrm{ml}$; erythrocyte sedimentation rate (ESR) $7 \mathrm{~mm} / \mathrm{hr}$; white cell count $7,700 / \mathrm{cu}$. $\mathrm{mm}$; serum calcium $10.3 \mathrm{mg} / 100 \mathrm{ml}$; ; alkaline phosphatase 38 King Armstrong (KA) units/100 ml. (normal less than 10). Wassermann reaction (WR) was negative.

Radiographs confirmed the changes of advanced Paget's disease of the left tibia. In the spine the sixth and tenth thoracic vertebrae were sclerotic and partially collapsed. At the upper level there was a dense paravertebral mass. Lumbar route myelography showed complete obstruction at the level of the upper border of the seventh thoracic vertebra. CSF protein was $169 \mathrm{mg} / 100 \mathrm{ml}$. and there was no pleocytosis.

At operation (Mr. J. Hankinson) the bone of the sixth thoracic vertebra was pinker and more vascular than that of adjacent vertebrae. The pedicles of T5, 6 , and 7 vertebrae were removed and the cord well decompressed.

Biopsy confirmed the diagnosis of Paget's disease. After operation there was some improvement in the function of his legs and the back pain was relieved. At six month follow-up improvement was maintained, although some leg weakness remained. 
CASE 2

A 53 year old male was admitted with a six month history of increasing difficulty in walking and a sensation of tight bands around his legs. Mid-dorsal back pain accentuated by coughing had been present for one month. No sphincter disturbance had been noted.

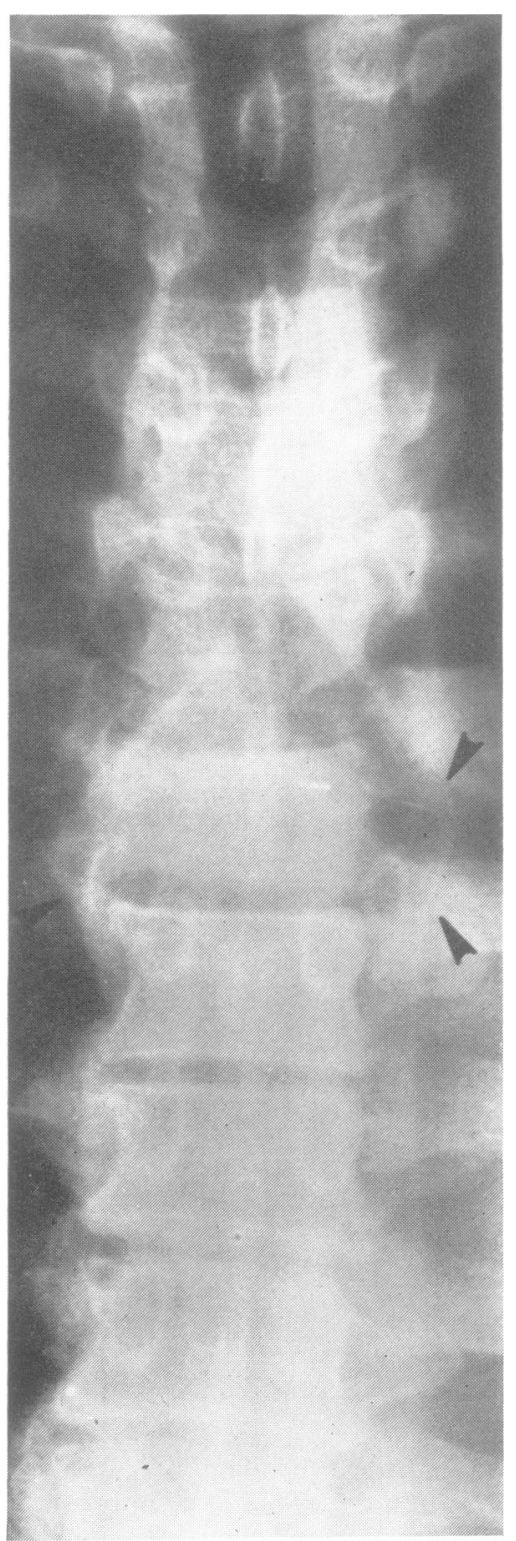

FIG. 1. Anteroposterior radiograph showing bony sclerosis and collapse with paravertebral swellings.
On examination, a moderate spastic paraparesis with impairment of joint position and vibration sense in the legs was present. He had impairment of light touch and pain and temperature sense to the level of the tenth thoracic dermatome. Sensation was preserved in the lower sacral segments.

Investigations revealed: haemoglobin $14.2 \mathrm{~g} /$ $100 \mathrm{ml}$.; ESR $19 \mathrm{~mm} / \mathrm{hr}$; white cell count 8,200/cu. $\mathrm{mm}$; serum calcium $10.2 \mathrm{mg} / 100 \mathrm{ml}$; ; alkaline phosphatase $145 \mathrm{KA}$ units/100 ml.; WR negative.

Radiography showed the changes of Paget's disease affecting the coracoid process of the left scapula. There was sclerosis and collapse of the body of the ninth thoracic vertebra with associated paravertebral swelling (Figs 1 and 2).

Lumbar route myelography revealed partial obstruction at the level of the upper border of the body of the tenth thoracic vertebra (Fig. 2). CSF protein was $222 \mathrm{mg} / 100 \mathrm{ml}$., sugar $66 \mathrm{mg} / 100 \mathrm{ml}$. and there was no pleocytosis.

At operation (Mr. Hankinson), laminectomy from the eighth to the tenth thoracic vertebrae was performed. The laminae of the ninth vertebra were soft and vascular. Initial post-operative progress was slow and the patient required a short period of $\sigma$ catheterization. However, at follow-up three and sixo $\infty$ months later, marked improvement in the pre웅

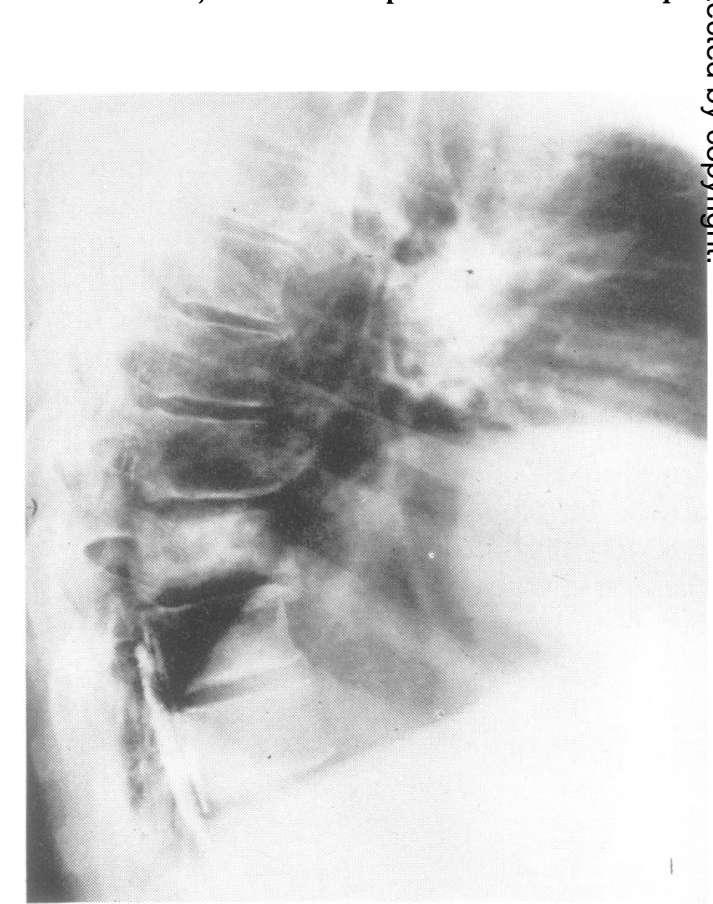

FIG. 2. Lateral radiograph showing bony sclerosis with myelographic obstruction. 
operative signs was noted, although some disability remained. Histological examination of the biopsy material again confirmed the diagnosis of Paget's disease.

\section{CASE 3}

A 59 year old man was initially admitted to hospital in September 1969 with a three month history of increasing weakness of his legs up till a few weeks before admission when he began to notice improvement. He had a mild spastic tetraparesis and radiographs of his cervical spine showed moderate spondylotic changes. In view of his apparent spontaneous improvement myelography was not undertaken and he was discharged with a diagnosis of cervical myelopathy. He was readmitted in April 1970 with a history of recurrence of walking difficulty over a two month period. There was no sphincter disturbance, although he had been impotent for six months.

On examination a moderately severe spastic paraparesis was present and in addition there was pathological increase in the tendon reflexes in the upper limbs. There was impairment of pain and temperature sensation below the level of the first thoracic dermatome. Joint position sense was impaired in the legs and sweating was impaired below the level of the nipples. However, orthostatic hypotension was absent and the blood pressure response to the Valsalva manoeuvre was normal.

Investigations revealed: haemoglobin $16 \cdot 2 \mathrm{~g} / 100$ $\mathrm{ml}$.; ESR $6 \mathrm{~mm} / \mathrm{hr}$; white cell count $6,500 / \mathrm{cu}$. mm; serum alkaline phosphatase $35 \mathrm{KA}$ units $/ 100 \mathrm{ml}$.; WR negative.

Radiography of the cervical spine showed moderately severe spondylosis. At lumbar route myelography there was complete obstruction at the lower border of the seventh cervical vertebra and in view of this tomograms of the seventh cervical vertebra were obtained. These showed expansion and sclerosis of the vertebral body. CSF protein was $426 \mathrm{mg} / 100$ $\mathrm{ml}$. with no pleocytosis.

At operation (Mr. R. Kalbag) the laminae of the seventh cervical vertebrae were found to be expanded and soft. Laminectomy was required as high as $\mathrm{C} 4$ vertebra before normal cord pulsation could be observed.

Postoperative progress was satisfactory and on discharge improvement was noted in the paraparesis, although the sensory impairment was unchanged. The bone biopsy at the time of operation showed unequivocal changes of Paget's disease.

\section{DISCUSSION}

The first two cases are unusual in that the his- tories were short (four and six months respectively) yet both had signs of moderately severe cord compression. Even early operation in these cases, however, resulted in only limited return of function. In both cases the history, signs, and the radiological appearance of the vertebral bodies might have suggested malignant disease. However, the presence of the paraspinal masses and the involvement of the laminae demonstrated radiologically left no doubt as to the diagnosis of Paget's disease, making surgical decompression mandatory.

The clinical features of the third case are complicated by the fact that he had advanced cervical spondylosis and this was the diagnosis initially entertained. The spontaneous improvement before his first admission was so striking that myelography was unfortunately not done at this stage. However, when he subsequently deteriorated and was readmitted, the myelogram showed an unexpected block at C7 vertebra. Because of this tomography was performed demonstrating changes of Paget's disease affecting the body of $\mathrm{C} 7$ vertebra, although no paraspinal mass or laminal involvement could be seen.

The three cases conform in a number of ways to the pattern described by most authors (Latimer et al., 1953; Miller, 1967; Siegelman et al., 1968; Feldman and Seaman, 1969). All were males in the usual age group and none was known to have Paget's disease until symptoms of spinal cord compression developed. Although all had a shorter than average history, each had a moderately severe deficit.

Two of our cases, in common with a number of those previously described, had histories and other features strongly suggestive of extradural metastasis (Siegelman et al., 1968; Direkze and Milnes, 1970). While the latter are often subjected to decompression, radiotherapy is a common alternative treatment without histological conformation of the diagnosis (Millburn, Hibbs, and Hendrickson, 1968) and the importance of recognizing these odd cases of Paget's disease is therefore stressed. The radiological demonstration of a paraspinal mass with neural arch involvement is undoubtedly the most vital clue to the diagnosis (Latimer et al., 1953; Direkze and Milnes, 1970). 
We thank Dr. D. A. Shaw and Dr. D. D. Barwick for permission to publish these cases, and it is a pleasure to acknowledge the assistance of Dr. Shaw in preparing this report.

\section{REFERENCES}

Direkze, M., and Milnes, J. N. (1970). Spinal-cord compression in Paget's disease. British Journal of Surgery, 57, 239-240.

Feldman, F., and Seaman, W. B. (1969). The neurologic complications of Paget's disease of the cervical spine. American Journal of Roentgenology, Radium Therapy, and Nuclear Medicine, 105, 375-382.

Hartman, J. T., and Dohn, D. F. (1966). Paget's disease of the spine with cord or nerve-root compression. Report of six cases. Journal of Bone and Joint Surgery, 48A, 10791084.

Latimer, F. R., Webster, J. E., and Gurdjian, E. S. (1953). Osteitis deformans with spinal cord compression. Report of three cases. Journal of Neurosurgery, 10, 583-589.

Millburn, L., Hibbs, G. G., and Hendrickson, F. R. (1968). Treatment of spinal cord compression from metastatic carcinoma. Cancer, 21, 447-452.

Miller, J. D. (1967). Spinal compression due to Paget's disease of bone. Scottish Medical Journal, 12, 441-445.

Siegelman, S. S., Levine, S. A., and Walpin, L. (1968). Paget's disease with spinal cord compression. Clinical Radiology, 19, 421-425.

Turner, J. W. Aldren (1940). The spinal complications of Paget's disease. Brain, 63, 321-349.

Wyllie, W. G. (1923). The occurrence in osteitis deformans of lesions of the central nervous system, with a report of four cases. Brain, 46, 336-351. 